\title{
ウォッシュロードによる貯水池堆砂の二次元数值計算
}

Two Dimensional Simulation of Reservoir Sedimentation

due to Wash Load

藤田 正治*・道上 正䂓 ${ }^{* *} \cdot$ 檜谷 治***・三木 敦史 ${ }^{* * * *}$

By Masanori MICHIUE, Masaharu FUJITA, Osamu HINOKIDANI and Atsushi MIKI

\begin{abstract}
A 2-dimensional numerical method for the simulation of reservoir sedimentation due to wash load, which is based on a 3-dimensional model for the flow and sediment concentration is presented. Firstly the validity of the equation of the entrainment rate was discussed with a 1-dimensional simulation of reservoir sedimentation. Secondly the 2-dimensional model was applied to a simulation of reservoir sedimentation in a field. The main and secondary flows in a non-uniform channel were calculated precisely and the distribution of the simulated deposition depth was in good a greement with the observed data.

Keywords: reservoir sedimentation, entrainment rate, wash load, 3-D flow model, 2-D bed variation model
\end{abstract}

1.はじめに

従来、貯水池堆砂の予測計算法は、主として一次元河床変動計算に基づき提案されてきた。また、堆砂の 長期予测をする場合には計算時間の関係上一次元解析を用いざるを得ない場合が多い。1)、2 しかし、効率 的な堆砂対策を実行するにあたって、より詳細な堆砂形状を知りたいような場合には二次元堆砂計算法が必 要となる。本研究では、とくにウォッシュロードのみが流入する場合の貯水池堆砂の二次元堆砂計算法を流 れおよびゥォッシュロード濃度の三次元解析に基づいて提示するすのである。

本文では、まず、堆砂形状の計算精度を左右する拡散方程式の河床境界条件について検討する。すなわち、 従来提案されている河床砂粒子の浮上率のウォッシュロードの堆砂計算に対する適応性について吟味すると ともに、簡便な境界条件の設定法についても検討する。ついで、二次元堆砂計算法の基礎式を提示し、実貯 水池の堆砂再現計算に適用し、その有効性、問題点について検討する。

\footnotetext{
* 正会員 工博 鳥取大学助教授 工学部土木工学科

（干680 鳥取市湖山町南4-101）

** 正会員 工博 鳥取大学教授 工学部土木工学科

*** 正会員 工博 鳥取大学助手 工学部土木工学科

**** 正会員 工修 神戸市役所
} 


\section{2. 拡散方程式の河床条件}

2.1 従来の浮上率の式の適応性

拡散方程式の境界条件式は $\varepsilon z \partial \mathrm{C} / \partial \mathrm{z}=-\mathrm{E}$ であるので、河床砂粒子の浮上率の計算精度を高めるこ とが重要である。ここに、 $\varepsilon_{z}:$ 拡散係数、 $\mathrm{C}:$ 濃度、 $\mathrm{z}$ : 鉛直方向の座標、 $\mathrm{E}:$ 浮上率である。従来、浮 遊砂の基準点濃度式を導く際に、浮上率の計算式が芦田・道上 ${ }^{3)}$ 、I takura・Ki shi ${ }^{4}$ 、芦田・藤田 ${ }^{5}$ らによ って提案されている。ここでは、次に示す芦田・藤田の提示した浮上率の式のゥォッシュロードの堆砂計算 に対する適応性について検討する。

$$
\mathrm{E}=\frac{2}{3} \mathrm{Kp}_{+} \sqrt{\frac{6}{\pi} \frac{1}{\mathrm{~s}+1}} \int_{\eta_{0}}^{\infty} \mathrm{u} * \sqrt{\mathrm{c} \mathrm{k}^{2} \eta-\frac{\pi}{8} \mathrm{C}_{\mathrm{DO}} \xi_{0}^{2}} \frac{1}{\sqrt{2 \pi}} \exp \left(-\frac{1}{2} \eta^{2}\right) \mathrm{d} \eta
$$

ここに、K $=0.035 、 \eta_{0}=(\pi / 8) \mathrm{C}_{\mathrm{Do}_{0}} \xi_{0}{ }^{2} /\left(\mathrm{ck}^{2}\right) 、 \mathrm{C}_{\mathrm{D}_{0}}=2+24 \nu /\left(\mathrm{w}_{\mathrm{o}} \mathrm{d}\right) 、 \xi_{0}=\mathrm{w}_{\mathrm{o}} / \mathrm{u}_{*} 、 \mathrm{~s}=\sigma / \rho-1 、$ $\mathrm{p}_{\mathrm{t}}:$ 粒径 $\mathrm{d}$ の粒子の混合割合、 $\nu$ : 水の動粘性係数、 $\sigma 、 \rho:$ 砂及び水の密度、 $\mathrm{u}_{*}$ : 摩擦速度、 $\mathrm{c}:$ 揚圧 力係数、 $\mathrm{k}$ : 遮蔽係数、 $\mathrm{w} 。$ : 粒子の沈降速度である。 $\mathrm{c}$ および $\mathrm{k}$ はそれぞれ砂粒レイノルズ数 $\mathrm{R}$ *および砂 の存在高さの関数であるが、ここでは $\mathrm{R} * 5$ に対する $\mathrm{c}=2.5$ と遮蔽のない状態に対する $\mathrm{k}=1.0$ を用いる。

なお、式(1)において $\mathrm{E}=0$ になる条件、すなわち、浮遊限界に対する摩擦速度は次式で表される。

$$
\frac{\mathrm{u}_{* \mathrm{so}_{0}}}{(\sigma / \rho-1) \mathrm{gd}}=\frac{\pi}{6} \frac{1}{3 \mathrm{ck}^{2}}
$$

\section{ここに、 $\mathrm{u}$ *soは浮遊限界摩擦速度である。}

図ー 1 は、粒径5、10、50、100 $\mu \mathrm{m}$ に対して $\mathrm{E} / \mathrm{w}$ 。を計算した結果を示したもので、参考のために芦田 ・道上の結果（粒径に依存せず）も示している。式(1) では、粒径によって浮遊限界の值が異なり、また粒 径が小さいほど浮遊限界付近でわずかな掃流力の增加によって浮上率が急激に増加する傾向が見られる。

さて、式(1) の適合性を実貯水池の 1 年間の堆砂の一次元再現計算によって検証する。ただし、ウォッシ ニロードの濃度は水深方向に一定として一次元解析され、 堆砂はウォッシュロードの沈降率（C（x） Wo） と浮上 率の差のみから計算された。ここに、 $\mathrm{C}(\mathrm{x}): \mathrm{x}$ 地点に おける濃度である。また、眝水池への流入土砂量は $\alpha Q^{2} て ゙$ 与えた。ここに、 $\alpha$ : 土砂生産特性に関する係数で、 $2 \times$ $10^{-5}$ (m-s単位) とする。流量は再現期間中の洪水の平均值 $200 \mathrm{~m}^{3} / \mathrm{s}$ 、貯水池水位は洪水期制限水位を用いた。洪水 時間は、ウォッシュロードの流入量が実績値に等しくなる ように250 時間とした。計算において河床が洗掘されると きは $\mathrm{E}=\mathrm{C}(\mathrm{x}) \mathrm{w}$ 。とし、河床が洗掘されないように した。ウォッシュロードの粒子は $5 \mu \mathrm{m} 、 12.5 \mu \mathrm{m}$ おび 45 $\mu \mathrm{m}$ の 3 つの階級に分割され、それぞれの割合を $25 \% 、 45$ \%、30\%とした。

図ー 2 は、前述の条件を用いて計算した堆砂形状の計算 值と観測值を示したものである。計算値は観測值を良く再 現しており、式(1) の妥当性が示唆される。また、同図に は堆積物に含まれる $5 \mu \mathrm{m} 、 12.5 \mu \mathrm{m}$ および $45 \mu \mathrm{m}$ の粒径

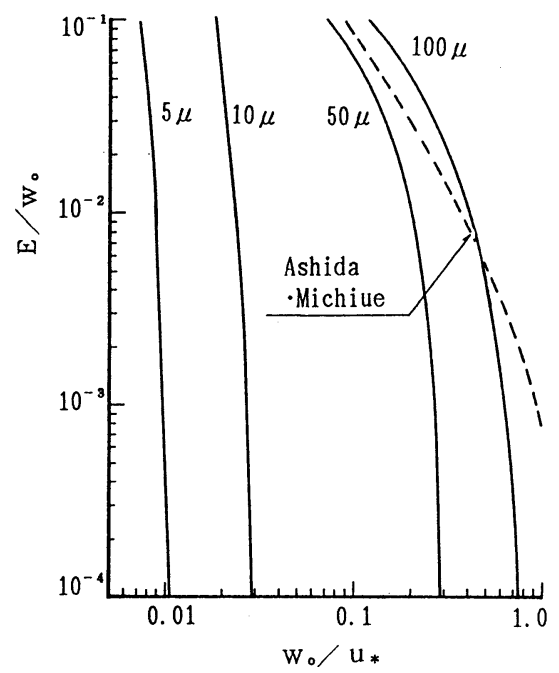

図-1 浮上率の計算結果 
の含まれる割合の計算值と観測值も示している。計算值は観測値と少し異なるが、粒度の分級過程がおおよ そ再現できている。

ついで、本研究では粒径を 3 分割しているがその必要性について若干検討する。図ー 3 は、粒径を分割せ ず平均粒径 $17 \mu \mathrm{m}$ の一様粒径として計算した結果である。一様粒径の場合は図ー 2 に比べて下流に多くの堆 積が見られ良好な再現性が得られたとは言い難い。これは、図ー1に示すように微細砂では粒径のわずかな 違いによって浮遊限界の条件が大きく異なるためである。

2 . 2 浮遊限界を使った河床条件

眝水池内では極端な水位低下のとき以外は堆砂の侵食は顕著でないので、侵食がないことを前提とし、浮 遊限界を境にして純堆積または河床変動なしとする境界条件を考える。すなわち、 $\mathrm{u}$ *く $\mathrm{u} *$ *.。の箇所では $\mathrm{E}$ $=0$ (純堆積)、 $\mathrm{u}_{*}>\mathrm{u}_{*}$.。の箇所では $\mathrm{E}=\mathrm{C}$

（x）w。（河床変動なし）とする。この条件を 使った堆砂形状の計算結果は図ー4のようであり、 浮上率を考虑した結果とほぼ同様である。これは、 河床が洗掘されないという仮定のもとに計算され ており、また微細砂の浮上率が、浮遊限界付近で 急激に変わるため、浮上率を計算してもわずかな u *の差で純堆積または河床変動なしの条件にな るためである。

以上のことから、ゥォッシュロードのような微 細な砂粒子による堆砂計算においては、浮上率よ りる浮遊限界を正確に予測することが重要であり、 $\mathrm{u}_{*}<\mathrm{u} *$ 。ののとき $\mathrm{E}=0$ （純堆積）、 $\mathrm{u}_{*}>$

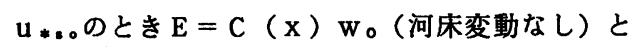
して河床条件を簡略化しても結果にさほど影響を 与えないことが分かった。

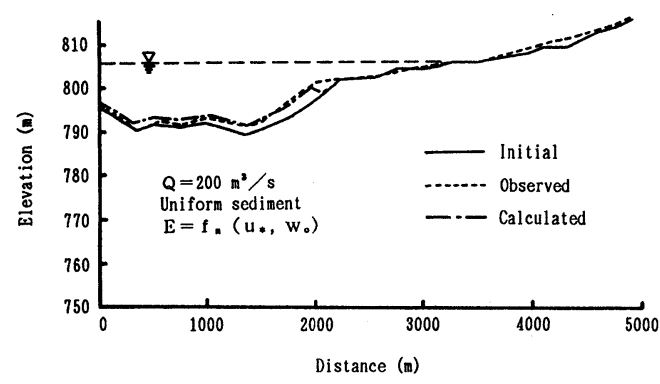

図- 3 堆砂形状の計算值と観測值

3. 二次元堆砂計算法

\section{1 非定常三次元流れの解析}

基礎方程式は連続式と運動方程式であり、図- 5 のような座標系のもとに次のように表される。

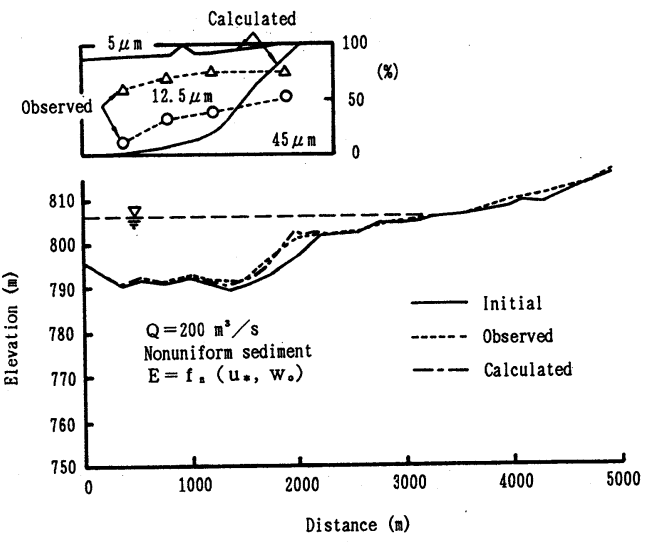

図-2 堆砂形状の計算値と観測值
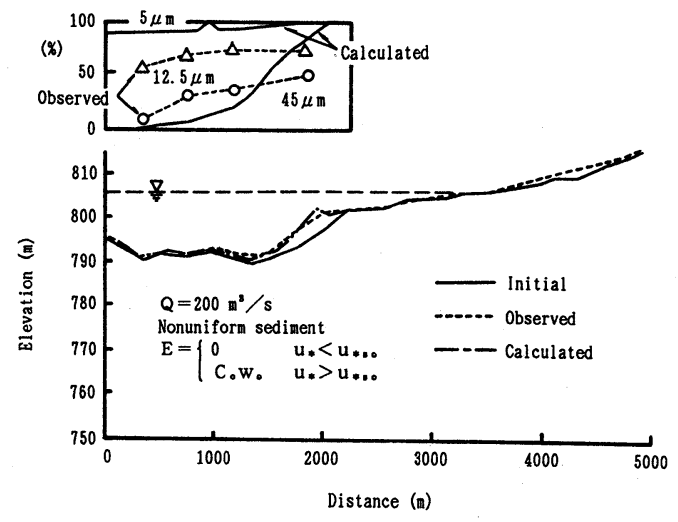

図-4 堆砂形状の計算值と観測値

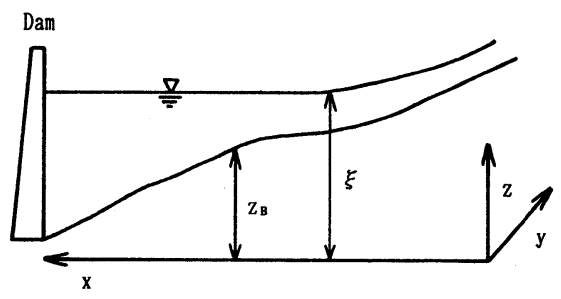

図-5 座標系 


$$
\begin{aligned}
& \frac{\partial \mathrm{u}}{\partial \mathrm{x}}+\frac{\partial \mathrm{v}}{\partial \mathrm{y}}+\frac{\partial \mathrm{w}}{\partial \mathrm{z}}=0 \\
& \frac{\partial \mathrm{u}}{\partial \mathrm{t}}+\mathrm{u} \frac{\partial \mathrm{u}}{\partial \mathrm{x}}+\mathrm{v} \frac{\partial \mathrm{u}}{\partial \mathrm{y}}+\mathrm{w} \frac{\partial \mathrm{u}}{\partial \mathrm{z}}+\mathrm{g} \frac{\partial \xi}{\partial \mathrm{x}}-\frac{\partial}{\partial \mathrm{z}}\left(\mathrm{A}_{\mathrm{v}} \frac{\partial \mathrm{u}}{\partial \mathrm{z}}\right)-\frac{\partial}{\partial \mathrm{x}}\left(\mathrm{A}_{\mathrm{h}} \frac{\partial \mathrm{u}}{\partial \mathrm{x}}\right)-\frac{\partial}{\partial \mathrm{y}}\left(\mathrm{A}_{\mathrm{h}} \frac{\partial \mathrm{u}}{\partial \mathrm{y}}\right)=0 \\
& \frac{\partial \mathrm{v}}{\partial \mathrm{t}}+\mathrm{u} \frac{\partial \mathrm{v}}{\partial \mathrm{x}}+\mathrm{v} \frac{\partial \mathrm{v}}{\partial \mathrm{y}}+\mathrm{w} \frac{\partial \mathrm{v}}{\partial \mathrm{z}}+\mathrm{g} \frac{\partial \xi}{\partial \mathrm{y}}-\frac{\partial}{\partial \mathrm{z}}\left(\mathrm{A}_{\mathrm{v}} \frac{\partial \mathrm{v}}{\partial \mathrm{z}}\right)-\frac{\partial}{\partial \mathrm{x}}\left(\mathrm{A}_{\mathrm{h}} \frac{\partial \mathrm{v}}{\partial \mathrm{x}}\right)-\frac{\partial}{\partial \mathrm{y}}\left(\mathrm{A}_{\mathrm{h}} \frac{\partial \mathrm{v}}{\partial \mathrm{y}}\right)=0
\end{aligned}
$$

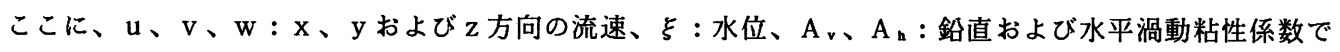
ある。式(3)を河床 $\left(\mathrm{z}=\mathrm{z}_{\mathrm{B}}\right)$ から水面 $(\mathrm{z}=\xi)$ までと河床から任意の高さまで積分すると次式を得る。

$$
\int_{Z_{B}}^{\xi}\left(\frac{\partial u}{\partial x}+\frac{\partial v}{\partial y}\right) d z+\left.w\right|_{\xi}-\left.w\right|_{Z_{B}}=\left.0 \quad(6) \quad w\right|_{Z}=\left.w\right|_{Z_{B}}-\int_{Z_{B}}^{Z}\left(\frac{\partial u}{\partial x}+\frac{\partial v}{\partial y}\right) d z
$$

以上の式 (4) (7)の 4 つの式より 3 次元流れが数值計算される。鉛直方向および水平方向の渦動粘性係数

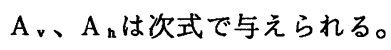
$A_{v}=\kappa u_{* o} z^{\prime}\left(1-z^{\prime} / h\right)$
(8)
$A_{h}=\kappa u_{* o} h_{\circ} / 6$

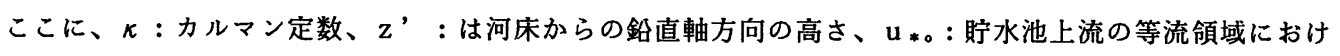
る摩擦速度、 $\mathrm{h}$ 。: 貯水池上流の等流水深である。

水面および河床での境界条件は以下のようである。
$\left.A_{v} \frac{\partial u}{\partial z}\right|_{\xi}=0$
$\left.A_{v} \frac{\partial v}{\partial z}\right|_{\xi}=0$
$\frac{\partial \xi}{\partial \mathrm{t}}+\left.\mathrm{u}\right|_{\xi} \frac{\partial \xi}{\partial \mathrm{x}}+\left.\mathrm{v}\right|_{\xi} \frac{\partial \xi}{\partial \mathrm{y}}=\left.\mathrm{w}\right|_{\xi}$
$\left.\mathrm{u}\right|_{\mathrm{z}_{\mathrm{B}}}=\left.\mathrm{v}\right|_{\mathrm{z}_{\mathrm{B}}}=\left.\mathrm{w}\right|_{\mathrm{z}_{\mathrm{B}}}=0$

上流端においては所定の流量を与え、下流端では初期の貯水池水位と放流量を与える。

3. 2 ウォッシュロードの非定常三次元拡散過程の解析

ウォッシュロードの三次元拡散方程式は次のようである。

$$
\frac{\partial \mathrm{C}}{\partial \mathrm{t}}+\mathrm{u} \frac{\partial \mathrm{C}}{\partial \mathrm{x}}+\mathrm{v} \frac{\partial \mathrm{C}}{\partial \mathrm{y}}+\mathrm{w} \frac{\partial \mathrm{C}}{\partial \mathrm{z}}==\frac{\partial}{\partial \mathrm{x}}\left(\varepsilon_{\mathrm{x}} \frac{\partial \mathrm{C}}{\partial \mathrm{x}}\right)+\frac{\partial}{\partial \mathrm{y}}\left(\varepsilon_{\mathrm{y}} \frac{\partial \mathrm{C}}{\partial \mathrm{y}}\right)+\frac{\partial}{\partial \mathrm{z}}\left(\varepsilon_{\mathrm{z}} \frac{\partial \mathrm{C}}{\partial \mathrm{z}}\right)+\mathrm{w}_{0} \frac{\partial \mathrm{C}}{\partial \mathrm{z}}
$$

ここに、 $\mathrm{C}:$ 濃度、 $\mathrm{t}:$ 時間、 $\varepsilon_{\mathrm{x}} 、 \varepsilon_{\mathrm{y}} 、 \varepsilon_{\mathrm{z}}: \mathrm{x} 、 \mathrm{y}$ および $\mathrm{z}$ 軸方向の拡散係数である。拡散係数は流れ の平均渦動粘性係数と等しいあのとし、 $\varepsilon_{\mathrm{x}}=\varepsilon_{y}=\varepsilon_{z}=\kappa \mathrm{u}_{* 0} \mathrm{~h} 0 / 6$ とする。

境界条件は、貯水池入り口、水面および底面で次のようである。

$$
\mathrm{C}_{\mathrm{m}} \mathrm{Q}=\alpha \mathrm{Q}^{2} \quad \text { (13) }\left.\quad \varepsilon_{2} \frac{\partial \mathrm{C}}{\partial \mathrm{z}}\right|_{\xi}+\left.\mathrm{W}_{\mathrm{O}} \mathrm{C}\right|_{\xi}=0 \quad \text { (14) }\left.\quad \varepsilon_{2} \frac{\partial \mathrm{C}}{\partial \mathrm{z}}\right|_{\mathrm{Z}_{\mathrm{B}}}=-\mathrm{E}
$$

濃度分布が計算されると、沈降率と浮上率の差として堆積量の分布が計算される。なお、流れと濃度の基 礎方程式は、時間的にはFractional Step Finite Difference Method、空間的には、鉿直方向に有限要素法、 水平方向に差分法を用いる。ただし、移流項には風上差分法を使用する。なお、計算法は、道上・檜谷 ${ }^{\text {》。 }}$ あのと同様である。 


\section{3 . 3 再現計算結果}

河床の初期条件は図ー6に示すとおりで、この領域を流下方向に $100 \mathrm{~m} 、$ 横断方向に $50 \mathrm{~m}$ の長方形メッシュ で分割した。計算に用いた諸定数、流量、水位は、一次元計算の結果が良好であったのでそれと同様にした が、洪水時間が 250 時間必要であるため計算時間が非常に多くかかり、実際上計算することができない。そ こで、計算時間を縮小するために次のような便宜的な洪水を設定した。すなわち、洪水時間を 250 時間 の $1 / 25$ にあたる 10 時間とし、その後流量 $100 \mathrm{~m}^{3} / \mathrm{s}$ の清水を 12 時間通水した。 1 年後の堆積厚は、この洪水が 25 回発生するとして 1 洪水の堆積厚を25倍して近似した。流れは洪水中は定常とし、清水流入後4 時間までは 非定常、その後は定常とした。また、濃度はつねに非定常計算した。

まず、流量 $200 \mathrm{~m}^{3} / \mathrm{s}$ に対する定常流の水面での流速べクトルを図-7 に示す。ダム上流 $2000 \mathrm{~m}$ 地点の狭さ く部上流では、標高の高い河 床の存在のため右岸よりの流 れと左岸よりの流れに分かれ ているが、流れはほぼ擬似等 流状態である。㹟さく部下流 では、主流が左岸側により、 右岸側に大きな逆流領域が生 じている。なお、図示してい ないが水位を $7 \mathrm{~m}$ 上げると主流 はすう少し右岸側により、逆 流領域も小さくなった。

図一 $8(\mathrm{a}) \sim(\mathrm{c})$ は濁水流入 後2、6、18時間における底面 付近の濃度分布のコンター図 である。流入したウォッシュ ロードは、狭さく部までは擬 似等流区間であるため通水開 始後すぐに流送され、6 時間 後には眝水池全体に拡がった。 この移流拡散過程は、狭さく 部下流右岸の逆流による下流 から上流へと流送される過程 と、左岸の主流域に沿ったダ 么の方向に流送される過程に 分けられる。ついで、洪水終 了後 (10時間後) 上流より清 水が流入すると、濁水塊は下 流へ移動し、狭さく部より上 流では急激に濃度が減少する。 しかし、狭さく部下流の右岸 では流れが循環しており、ウ オッシュロードが流出しにく くなっている。

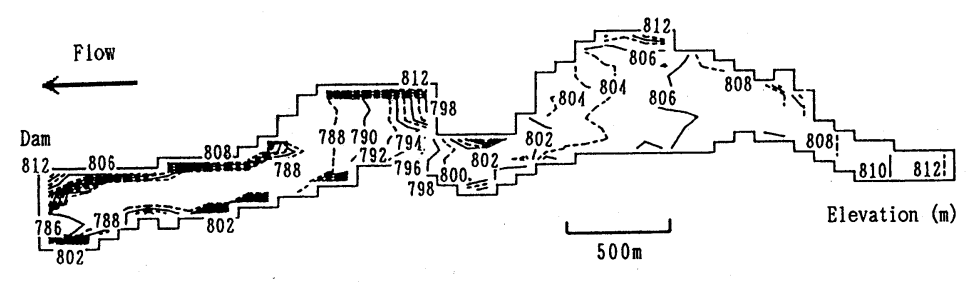

$$
\text { 図-6堆砂初期形状 }
$$

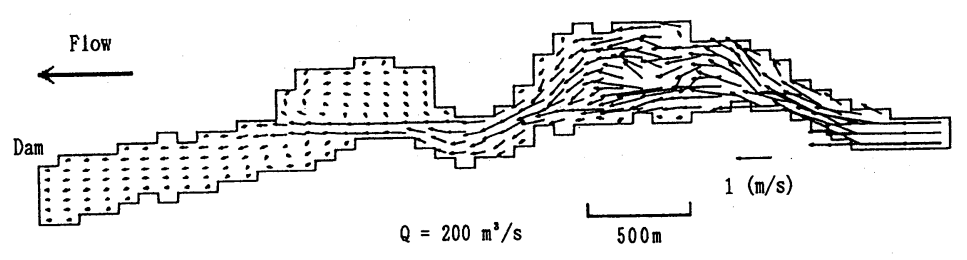

図-7表面流速ベクトル

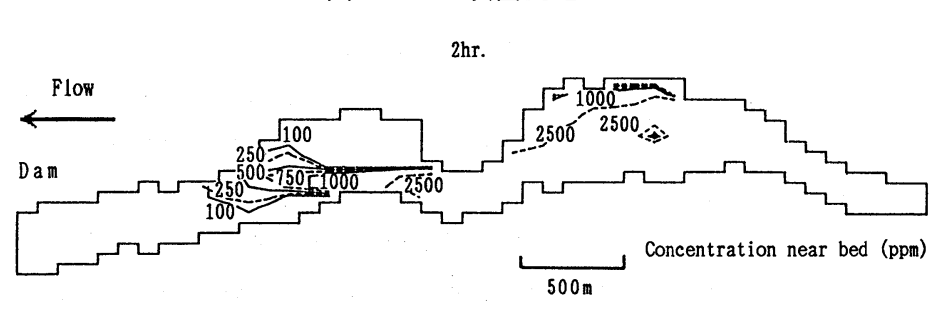

$6 \mathrm{hr}$.

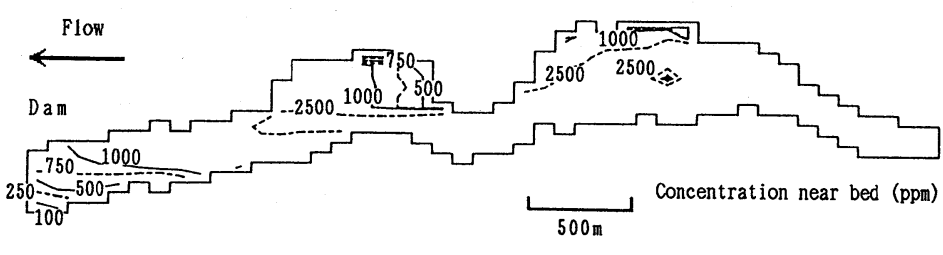

$18 \mathrm{hr}$.

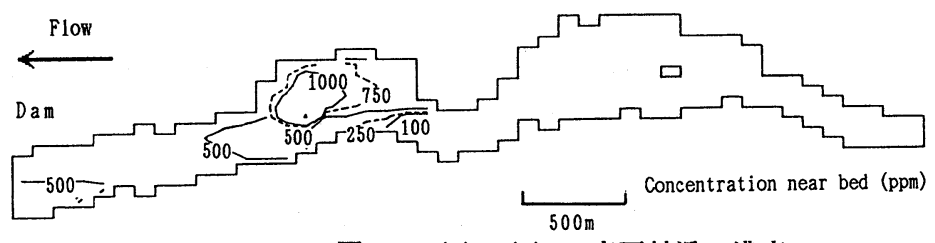

図-8 (a) (c) 底面付近の濃度 
図 -9 に 1 年後の堆積厚分 布の計算值を示す。この図と 堆積厚の 観測結果を 示した 図一 10 を 比較すると二次 元堆砂形状はほぼ再現できて いることがわかる。とくに堤 体付近の均一に堆積している 領域や狭さく部下流の逆流域 に多くの土砂が堆積している 点はよく再現できている。し かし、狭さく部直下流の堆積 場所が計算では観測結果に比 べて下流へずれている点が異

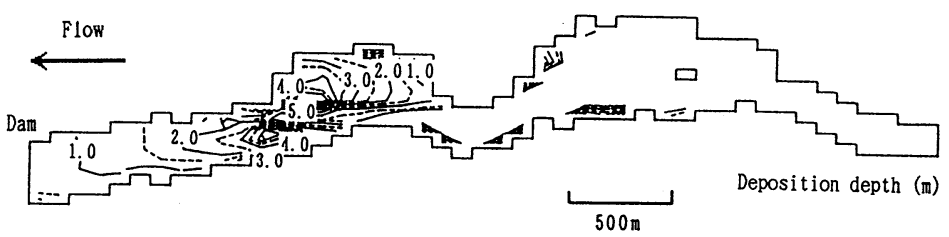

図-9 ウォッシュロードの堆積厚の計算值

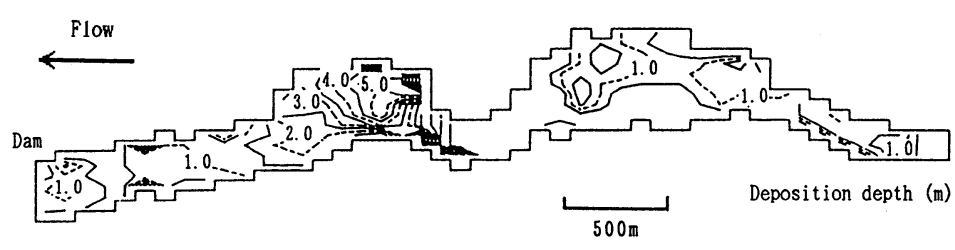

図ー1 0 ウォッシュロードの堆積厚の観測値 なっている。計算では、狭さ く部下流で、図ー 7 に示すように主流が左岸側に偏っているためこの箇所の堆積量が少なくなったすのと考 えられるが、これは水位や流量を一定とした影響が現れたるのと推察される。

以上のように、本二次元堆砂計算法は二次元的な堆砂形状の計算に有効であると言えるが、計算時間の関 係上洪水時間を縮小すると言うような便宜的な方法をとらざるを得なかった。現実には、一回の平均洪水時 間は25時間程度であるので、濃度の非定常性のため堆積量の分布に誤差が生じるおそれがあるが、4時間で ほぼ定常に達しているので、その影響は小さいるのと推察される。計算時間の短縮化または合理的な流量、 水位、洪水時間の設定法が今後の課題である。

\section{4.おわりに}

本研究は、ウォッシュロードによる貯水池堆砂の二次元計算法を提案し、その有効性や問題点を実貯水池 の堆砂再現計算により検討したすのである。以下に、得られた主要な成果を列挙する。

（1）ウォッシュロードのような微細な土砂は、粒径のわずかな差で浮遊条件が大きく異なるため、粒度 分布をいくつかの粒径階に分けて計算する方が計算精度の向上につながる。

（2）計算精度の向上のためには、河床砂の浮上率や浮遊限界を正確に予測することが肝要である。また、 ウォッシュロードのような微細砂の場合、堆砂の侵食が顕著でなければ、浮上率を計算しなくても、浮遊限 界を境にして純堆積または河床変動なし、として計算を簡略化することができる。

（3）非一様な河道では、弯曲部や狭さく部等において 2 次元的な堆砂形状がみられる。このような形状 は、本研究で提案したような 2 次元堆砂計算によってある程度再現し得る。

1）声田・岡部：貯水池堆砂の数值計算法に関する研究、京大防災研年報、第25号B-2、PP. $389 \sim 400 、 1982$.

2）芦田・藤田: 貯水池堆砂の数值シミュレーション、京大防災研年報、第30号B-2、pp. 457〜 474、1987.

3）声田・道上：浮遊砂に関する研究（1）、京大防災研年報、第13号B、pp. 233 242、1970.

4) Itakura Kishi : Open Channel Flow with Suspended Sediments, ASCE, HY8, pp. 1325-1342、1980.

5）昔田・藤田：平衡および非平衡浮遊砂量算定の確率モデル、土木論文集、第375号、PP. 107〜110、1986.

6) 道上・檜谷ら：湖における底泥の浮上と拡散に関する数值解析、第 42 回中四年講、pp. 190-191、1990. 